\title{
The Coordination Analysis of Information Sharing between Teachers and Students in WeChat Classroom
}

\author{
HUANG Ling \\ Shandong University of Finance and Economics \\ School of Accounting \\ Shandong, Jinan \\ hljnsd@sdufe.edu.cn
}

\begin{abstract}
The application of WeChat classroom has brought a new way for innovating teaching mode and educational management. This paper analyzes the dynamic decision-making process between teachers and students as well as between students and students in WeChat classroom, establishes a game model, and analyzes the best strategies for both parties. It finds that the unit score coefficient obtained by students is related to their performance contribution coefficient, risk aversion coefficient, effort coefficient, uncertainty degree of group environmental factors and so on. Through designing and implementing effective incentive contracts, teachers can promote students' active participation and improve the qualities of feedback and information sharing. Moreover, teachers can increase the number of students participating in the information sharing, improve the single value of performance score and the value of individual single loss of reputation caused by hitchhiking, which can better protect the continuous sharing behavior of WeChat group and ensure the harmonious and orderly development of WeChat classroom.
\end{abstract}

Keywords-WeChat classroom; Information sharing; Coordination; Incentive contract

\section{INTRODUCTION}

With the continuous updating and development of information technology, Human society has entered a new digital age. In 2014, there were seventy-seven million six hundred and ninety-nine thousand online education users, up 16 percent from a year earlier. In the coming years, online education users will continue to grow at a rate of more than $15 \%$, reaching 120 million by 2017, according to Erie Consulting. Nowadays, in the new media environment, WeChat is also slowly emerging in the field of education, emerging in the field of education, giving play to its role. $[1,2,3,4,5]$. WeChat not only has the general characteristics of open, interactive, real-time, and so on, but also has the characteristics of network platform. It also has the characteristics of convenient communication, flexible communication, concise content and so on, which is exactly in line with the value needs of students eager to communicate and willing to show themselves, which brings a new way for the development of innovative teaching mode and educational management.

WeChat classroom refers to the interactive teaching method of making use of WeChat group and WeChat public platform for teaching assistance, setting up micro-topics scientifically, organizing students to discuss and teachers to comment on. In adult WeChat classroom, the participants are teachers and students. In this paper, an evolutionary game model is established between teachers and students, students and students, and their respective optimal strategies are analyzed, and the effects and effects of relevant factors on the design of contract models are discussed for each model.

\section{COORDINATION BETWEEN TEACHERS AND STUDENTS}

\section{A. Model hypothesis and parameter definition}

In the WeChat classroom, teachers are the organizers, the core of coordination and play a leading role, which determines the development, continuation and evaluation of the activities, and is the party with more information. Understand and clarify the community level improvement and evaluation resulting from the sharing of learning knowledge. Between teachers and students, teachers require students to share their learning experiences and carry out learning feedback so that teachers can master the progress of students and evaluate the performance of students according to their feedback information. Students are the main body of knowledge sharing. Students can choose "share" and "do not share" learning experience. This paper studies the design of incentive contracts between teachers and students in this model. The influence of students' degree of effort and unit score coefficient on the design of contract variables is analyzed [8-10]. The model structure diagram is as follows:

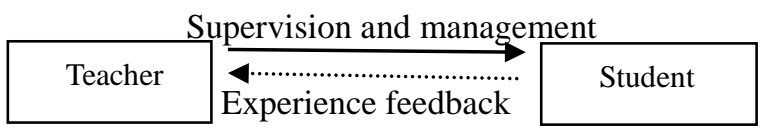

Fig. 1 A Schematic diagram of coordination between teachers and students

- Assume that WeChat class brings about an improvement in group performance, the output function of group performance is $R(\theta)=k \theta+\varepsilon$, which $\theta$ is the quality of learning experience information shared by students in WeChat class. Reflecting the degree of effort of the students; $k$ is Contribution factor for performance, A constant greater than $0 ; \varepsilon$ is uncertainty influencing factors of Group environment. Suppose $\varepsilon \in N\left(0, \delta^{2}\right)$. 
Assuming that both sides are rational economic people, the pursuit of their own performance (utility) is the greatest. Teachers are assumed to be risk-neutral, students risk aversion and $\rho$ absolute risk aversion.

- Teachers rated the students according to their shared feedback in the WeChat class. Assume that the rating criteria are linear forms of group performance: $\quad p(R)=a+b \theta,(0 \leq b \leq 1) \quad$,Among them, $P(R)$ is marks given by teachers to students when group performance output is $R$; $a$ is the minimum score for each student participating in the WeChat class group; $b$ is the unit scoring coefficient.

- The student's effort cost $c(\theta)$ is assumed to be a function of its shared feedback information quality $\theta$. Obviously, the higher the quality of information shared by students, the greater the effort cost. We might as well set up $c(\theta)=\frac{1}{2} \eta \theta^{2}$, here $\eta_{\text {Indicative effort coefficient, }}$ the larger the effort $\eta$, the greater the cost effectiveness of the same information quality.

- The benefit of assuming that students win in a group (get a good rating) is $w$.The probability of winning is $p_{0}$.This means that even if students choose not to share their learning experience, they will also receive the basic winning benefits $p_{0} w$ of WeChat class.

- $\pi_{t}$ is the benefit of teachers (representing the performance of the group) $\pi_{s}$ is student income, $E U$ is expected utility.

\section{B. Model analysis}

Based on the above assumptions, according to the relationship between risk attitude and utility function, the expected utility of teachers is equal to their expected income.

$$
\begin{aligned}
E U_{t} & =E \pi_{t}=E[(R(\theta))-p(R)] \\
& =E[(k \theta+\varepsilon)-a-b R]=k \theta-a-b k \theta
\end{aligned}
$$

Since students are risk-averse, their expected utility is equal to the expected income minus the risk cost [6-7]:

$$
\begin{aligned}
E U_{s} & =E \pi_{s}-\frac{1}{2} \rho b^{2} \delta^{2} \\
& =a+b k \theta-\frac{1}{2} \eta \theta^{2}-\frac{1}{2} \rho b^{2} \delta^{2}
\end{aligned}
$$

Based on the above assumption, we adopt reverse induction method. If students choose not to share their learning experience, the benefits will be as follows $p_{0} w$; if the learning experience is shared, the benefits $\lambda E U_{t}$ will be obtained. So when the following formula is established, the student chooses to share.

$$
\lambda E U_{t}-p_{0} w>0
$$

That is to say, the constraints of sharing learning experience for students' participation (IR) are as follows:

$$
a+b k \theta-\frac{1}{2} \eta \theta^{2}-\frac{1}{2} \rho b^{2} \delta^{2} \geq p_{0} w
$$

By sharing their learning experience and relying on the quality of their feedback information $\theta$, students strive for the best evaluation benefit of the teacher and thus obtain the expected utility.

$$
\begin{aligned}
E U_{s} & =E \pi_{s}-\frac{1}{2} \rho b^{2} \delta^{2} \\
& =a+b k \theta-\frac{1}{2} \eta \theta^{2}-\frac{1}{2} \rho b^{2} \delta^{2}
\end{aligned}
$$

Therefore, the incentive compatible constraint conditions for students (IC) are as follows:

$$
\theta^{*}=\underset{\theta}{\arg \max }\left(E U_{s}\right)
$$

If the derivative of the upper formula is equal to zero, then

$$
\text { the } \theta^{*} \text { must be satisfied: } \theta^{*}=\frac{b k}{\eta}
$$

Therefore, the problem for teachers is to select $\left(a^{*}, b^{*}\right)$ to solve the following optimization problems under given constraints (4) (5):

$$
\begin{aligned}
& \max _{a^{*}, b^{*}}\left(E \pi_{t}\right)=k \theta^{*}-a^{*}-b^{*} k \theta^{*} \\
& \text { s.t. }\left\{\begin{array}{l}
a^{*}+b^{*} k \theta^{*}-\frac{1}{2} \eta \theta^{* 2}-\frac{1}{2} \rho b^{* 2} \delta^{2} \geq p_{0} w, \\
\theta^{*}=\frac{b^{*} k}{\eta}
\end{array}\right. \\
& \text { c (9). Solution and revelation }
\end{aligned}
$$

Based on the above optimization problems, it can be concluded that:

$$
\max _{b^{*}}\left(E \pi_{t}\right)=\frac{k^{2} b^{*}}{\eta}-\frac{1}{2} \frac{k^{2}}{\eta} b^{* 2}-\frac{1}{2} \rho \delta^{2} b^{* 2}-p_{0} w
$$

In the upper form, the derivative $b^{*}$ is obtained by making it equal to 0 , and the solution is obtained.

$$
b^{*}=\frac{k^{2}}{k^{2}+\rho \eta \delta^{2}}
$$

Substitution (9) 


$$
\begin{aligned}
& a^{*}=\frac{\left(\rho \eta \delta^{2}-k^{2}\right) k^{4}}{2 \eta\left(k^{2}+\rho \eta \delta^{2}\right)^{2}}, \\
& \theta^{*}=\frac{k^{3}}{\left(k^{2}+\rho \eta \delta^{2}\right) \eta}
\end{aligned}
$$

The following is an analysis of $b^{*}$ with the changes of $k, \rho, \eta, \delta$.According to the (11) form, we get the following:

$$
\frac{\partial \beta}{\partial k}>0, \frac{\partial \beta}{\partial \rho}<0, \frac{\partial \beta}{\partial \delta}<0, \frac{\partial \beta}{\partial \eta}<0
$$

Revelation 1): The constraint of students participating in We Chat class to share their learning experience is that the effectiveness of participation in sharing $\lambda E U_{t}$ is higher than $p_{0} w$, otherwise the students refuse to share. When designing incentive contracts, teachers should fully estimate the value of $p_{0} w$, without affecting the development of WeChat classroom, through repeated testing of WeChat classroom activities, the probability of students not participating in sharing and getting high evaluation scores can be reduced as far as possible.

Revelation 2): It can be seen that the unit score coefficient obtained by students is related to their performance contribution coefficient, risk aversion coefficient and effort coefficient, uncertainty degree of group environment factors and so on. The greater the performance contribution coefficient of students' feedback information, the higher the evaluation of students, and the higher the students' attitude towards sharing feedback information, the more risk averse, the smaller the evaluation score and the less the effect on individual benefit. The greater the coefficient of the same effort cost, the greater the uncertainty of group environment, the smaller the evaluation intensity of students, the lack of incentive for learning experience sharing behavior, and the lower the quality of feedback information.

In the real WeChat classroom, teachers can increase the contribution coefficient of the group's overall performance output by increasing the unit score coefficient of students, and at the same time, try to provide various conditions to reduce the input cost of students' learning efforts. Measures such as reducing the occurrence of uncertainty in groups and reducing risks can enhance the effectiveness of incentive contracts, promote the effective implementation of knowledge sharing in groups, and improve the operation of WeChat classes. Further analysis of the formula (12) can be obtained:

$$
\begin{aligned}
& \frac{\partial \theta^{*}}{\partial \rho}=\frac{-\eta^{2} \delta^{2} \theta^{*}}{\rho \eta^{2} \delta^{2}}<0, \\
& \frac{\partial \theta^{*}}{\partial \eta}=\frac{-\left(k^{2}+2 \rho \eta \delta^{2}\right)}{k^{2} \eta+\rho \eta^{2} \delta^{2}}<0
\end{aligned}
$$

Revelation 3): In the case of asymmetric information, the quality of students' feedback and sharing information is expressed as the risk aversion coefficient of students and the reduction function of their own learning effort cost, with the increase of risk aversion and the increase of learning effort cost. The quality of students' feedback information tends to decline, which leads to the decline of group performance, which is not conducive to the effective implementation of incentive contracts.

It is not difficult to see that the above conclusions are interrelated. In practical applications, teachers can design and implement effective incentive contracts, promote students' active participation, take effective actions, and improve the quality of feedback and information sharing; on the other hand, Through the study of students' risk avoidance coefficient and unit score coefficient, the enthusiasm of students participating in WeChat class is improved, and the efficiency of sharing and feedback is increased, thus ensuring the harmonious and orderly development of WeChat classroom.

\section{COORDINATION between students and students}

\section{A. Model hypothesis and parameter definition}

In the WeChat class, there is also a relationship of cooperation and competition between students and students. The improvement of the performance of the whole WeChat group depends on the contribution of each member of the WeChat group. Students participate in the WeChat class. On the one hand, it makes up for the limitation of the teaching time and place, on the other hand, it can consult the instructor or share the learning experience among the students at any time. It solves the puzzling problems existing in the classroom learning or improves the understanding of the knowledge points, thus improving the individual performance and contributing to the improvement of the performance of the whole group. But at the same time, there is also a competitive relationship among the students. Every student wants to win in the group. There is a motive to hide or be unwilling to share the learning experience with others. The model structure is designed as follows:

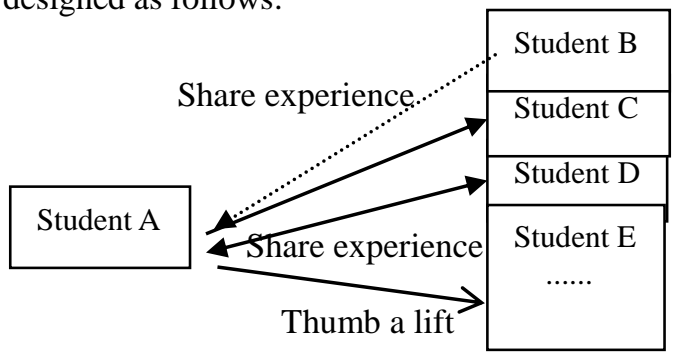

Fig. 2 A schematic diagram of coordination between students and students

In a group of WeChat classes, students study a course for a longer period of time and learn and share it many times. Everyone can decide whether to share their learning experience or not based on their past learning experience.

- Assume that each student benefits from an increase in the evaluation score resulting from the improvement in group performance. Conversely, the decrease of group performance also affects the income of each participant. The total number $n$ of people in the group, $t$ is the number of students who participate in the sharing of learning experience, and the others $n-t$ are the students who do not participate in the sharing and conceal their experience. 
- Assume that the benefit of students winning in a group is assumed to be $w$.The probability of winning is $p_{0}$.This means that even if students choose not to share their learning experience, they will also receive the unit winning benefits $p_{0} w$ of WeChat class.

- Students share their learning experience in groups, which will enhance their credibility. It increases the single value $Q$ of the guidance teacher's performance score and contributes to the overall performance $V$ of the group. At the same time, the students pay the cost $c$ of learning hard, reduce their probability $p_{1}$ of winning in the group, and at the same time, they will share $p_{2}$ with others. Win the chance to win the promotion.

- Assuming that students choose not to share their learning experience in the group, it will have a negative impact on other students, reduce the overall performance $\xi$ of the group, and the individual's single credibility $L$ will decline.

- $\pi_{1}$ is benefit of students share the benefits of learning experience, $\pi_{2}$ is benefit of students do not share the benefits of their study.

\section{B. Model analysis}

On the basis of the above assumptions, Among the WeChat groups with a total number $n$ of participants, the students selected to share the benefits of a single event are:

$$
\begin{gathered}
\pi_{1}=t Q+t V+\left[p_{0}-p_{1}+(t-1) p_{2}\right] w \\
-c-(n-t) \xi
\end{gathered}
$$

Students $A$ choose not to share the benefits of learning:

$$
\pi_{2}=(t V-L)+\left[p_{0}+t p_{2}\right] w-(n-t) \xi
$$

Only when $\pi_{1}>\pi_{2}$, the students choose to share their learning experience. We will get:

$$
t Q-\left(P_{1}+P_{2}\right) W-C>0
$$

That meet the formula (17), students will choose to share.

Assuming that in the WeChat group with a total number $n$ of members, a total of discussions $m$ were held, in which the non-sharing group $(n-t)$ was absent $k$, the students $A$ chose to share the benefits as follows:

$$
\begin{aligned}
\pi_{1}= & m\left\{t Q+t V+\left[p_{0}-p_{1}+(t-1) p_{2}\right] w\right. \\
& -c-(n-t) \xi\}
\end{aligned}
$$

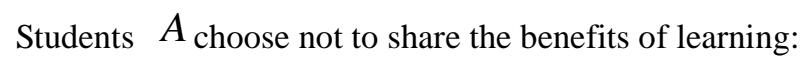

$$
\begin{aligned}
\pi_{2}= & k(t V-L)+(m-k)\left\{t V+\left[p_{0}+(t-1) p_{2}\right] w\right. \\
& -(n-t) \xi\}
\end{aligned}
$$

Only when $\pi_{1}>\pi_{2}$, the students $A$ choose to share their learning experience.

$$
\begin{aligned}
& m\left(t Q-p_{1} w-c\right)-k[(n-t) \xi-L \\
& \left.-p_{0} w-(t-1) p_{2} w\right]>0
\end{aligned}
$$

\section{Solutions and Enlightenment}

By synthesizing the above formula, we can draw the following enlightenment.

Revelation 1): In a single activity in WeChat class, students will choose to share their learning experience only if the formula (17) is satisfied. That is, $t Q>\left(p_{1}+p_{2}\right) w+c$ to be satisfied. Otherwise, the students refuse to share. On the one hand, teachers should fully estimate the value $w$ of incentive contracts when designing incentive contracts, without affecting the development of WeChat class, can reduce the probability of students winning high scores because they do not participate in sharing. On the other hand, students can be encouraged to share their learning experience by increasing the number of participants $t$ and increasing the score $Q$ of individual performance evaluation, so as to ensure the effective operation of WeChat classroom.

Revelation 2): At the same time, we note that the discussion in WeChat Group will not take place once, If the sharing is to continue, for students $A$, the probability of winning must be increased, that is to say, to satisfy: $-p_{1}+(t-1) p_{2}>0, t>\frac{p_{1}}{p_{2}}+1$, Because the level of difference between the students is not very large, $p_{1} \approx p_{2}$, we can obtain $t \geq 3$, That is, the number of people in the group must be at least 3 , the sharing within the group can be carried out and continued. In many activities of WeChat class, learners will choose to share their learning experience only if the formula (20) is satisfied. It can be seen that, increasing the number $t$ of students participating in the sharing, improving the performance score single value $Q$ and $L$ hitchhiking caused by the individual single decline in value, can better ensure the continued sharing behavior of WeChat group; On the other hand, reducing the $\operatorname{cost} c$ of students' learning efforts, reducing the number $(n-t)$ of hitchhikers and the negative effects of non-sharing behavior, all contribute to the improvement of the overall performance of the group. 


\section{CONCLUSION}

WeChat is not only a common tool for people's daily communication, but also because of the openness, interactivity and immediacy of its network platform, it fits the needs of students eager to communicate and willing to show their own value. This brings a new way to develop innovative teaching mode and educational management. WeChat classroom emerges as the times require. This paper analyzes the dynamic decision-making process between teachers and students and between students and students in WeChat classroom, and establishes a game model. The best strategies of both parties are analyzed, and the effect and influence of relevant factors on the design of contract model are discussed for each model, and some beneficial implications are obtained.

The learning of WeChat class is not just a game, in which the learning of a certain knowledge point, this kind of discussion and analysis will continue for a period of time until the beginning of the next knowledge point learning. We can't rule out the possibility of repeated learning in the future. This mode of sharing learning broadens the range of people who have been educated, and teachers can also get inspiration from it, and can further improve their teaching methods. With the improvement of WeChat platform, WeChat classroom will have a great influence on the future education model and educational methods, and will certainly play an important auxiliary role in all kinds of primary and secondary education.

\section{REFERENCES}

[1] LEE S W, LEE J.A comparative study of Kakao Story and Facebook: Focusing on use patterns and use motives. [J]. Telematics and Informatics. 2016.

[2] Rauniar, Rupak, Rawski, Greg, Yang, Jei, Johnson, Ben. Technology acceptance model (TAM) and social media usage: an empirical study on Facebook [J]. Journal of Enterprise Information Management. 2014 (1).

[3] Kong Yun; Liao Y; Zhi Yun; Xue Xiuzhen; Zhang Zhonghua. Research on Mobile Information Service of Library based on WeChat Public account [J] .Intelligence Journal 2013(09). (In Chinese)

[4] Zhu Xuewei; Zhu Yu; Xu Xiaoli, WeChat supported Mobile Learning platform Research and Design [J]. Distance Education in China. 2014(04). (In Chinese)

[5] Wang Xiaoling, A comparative study of task-driven collaborative learning supported by WeChat and QQ $[\mathrm{J}]$. Audio-visual Education Research.2013 (11). (In Chinese).

[6] Fangruo Chen, Awi Federgruen. Mean-variance analysis of basic inventory model [D]. Columbia University, 2000.

[7] Li Liang; Xie Binglei. Supervision and incentive in supply chain [J] .Application of system Engineering Theory and method, 2002, 12 (3).

[8] Shanshan; Tan Xiaohong; Xue Ke, an empirical study of Mobile Micro Learning based on WeChat Public platform: a case study of "data structure Public platform" [J] .Open Education Research 2015 (01).

[9] Wang Shuwei; Cao Ruye; Yang Mengqing; Chen Lijun, WeChat user Information sharing behavior Model and empirical study: an Analysis based on Information Ecology $[\mathrm{J}]$. Library and information work in 2016.

[10] Chen Fuji. Huang Jiangling. A study on herding effect of Internet Public opinion Communication based on Evolutionary Game $[\mathrm{J}]$.Information Journal, 2013 / 10. (In Chinese) 